eISSN 2444-7986

DOI: https://doi.org/10.14201/orl201784.15691

Caso clínico

\title{
TRAQUEOBRONCOPATÍA OSTEOCONDROPLÁSICA. DESCRIPCIÓN DE UN CASO
}

\section{Tracheobronchopathia osteochondroplastica. A case report.}

\author{
Candelas ÁLVAREZ-NUÑO; Raquel FERNÁNDEZ-MORAIS; Sara FERNÁNDEZ-CASCÓN; Luis \\ Ángel VALLEJO-VALDEZATE
}

Servicio de Otorrinolaringología y CCC. Hospital Universitario Río Hortega. Valladolid. España.

calvareznuno@hotmail.com

Fecha de recepción: 28 de enero de 2017

Fecha de aceptación: 20 de febrero de 2017

Fecha de publicación: 22 de febrero de 2017

Fecha de publicación del fascículo: 1 de diciembre de 2017

Conflicto de intereses: Los autores declaran no tener conflictos de intereses

Imágenes: Los autores declaran haber obtenido las imágenes con el permiso de los pacientes

Política de derechos y autoarchivo: se permite el autoarchivo de la versión post-print (SHERPA/RoMEO)

Licencia CC BY-NC-ND. Licencia Creative Commons Atribución-NoComercial-SinDerivar 4.0 Internacional

Universidad de Salamanca. Su comercialización está sujeta al permiso del editor

RESUMEN

Introducción y objetivo: Presentamos el caso clínico de una paciente diagnosticada de traqueobroncopatía osteocondroplásica(TOC). Revisamos la literatura existente. Descripción: Paciente mujer que consulta por halitosis secundaria a rinitis crónica atrófica unilateral. En el estudio nasofibroscópico se observan lesiones nodulares perladas en fosa nasal y tráquea. Solicitamos pruebas de imagen que describen de manera precisa estas lesiones a nivel traqueal. Resultados: Las imágenes endoscópicas y las pruebas radiológicas sugieren el diagnostico de TOC concomitante con rinitis crónica atrófica (ocena). Conclusiones: La TOC es una patología benigna. Cursa con lesiones y manifestaciones clínicas en vía aérea superior. Dada la infrecuencia de esta entidad hemos considerado justificada su publicación con el fin de dar a conocer esta entidad, cómo sospechar su diagnóstico, sus diagnósticos diferenciales y la posibilidad de manejo terapéutico.

PALABRAS CLAVE traqueobroncopatía osteocondrodisplásica; tráquea; ocena; rinitis

SUMMARY

Introduction and objective: We present the clinical case of a patient diagnosed with tracheobronchopathia osteochondroplastica. We review the existing literature. Description: Patient woman consulting for halitosis secondary to chronic unilateral atrophic rhinitis. In the nasofibroscopic study, nodular lesions are seen in the nasal cavity and trachea. We request imaging tests that accurately describe these lesions at the tracheal level. Results: Endoscopic imaging and radiological evidence suggest the diagnosis of concomitant TOC with chronic atrophic rhinitis (ozena). Conclusions: Tracheobronchopathia osteochondroplastica is a benign pathology. Curses with lesions and clinical manifestations in the upper airway. Given the infrequency of this entity, we have considered its publication justified in order to publicize this entity, how to suspect its diagnosis, its possible differential diagnoses and the possibility of therapeutic management. 


\section{INTRODUCCIÓN}

La traqueobroncopatía osteocondroplásica (TOC) es una enfermedad benigna e infrecuente. La incidencia real no es conocida, ya que a menudo cursa de forma asintomática o con sintomatología inespecífica [1]. Se caracteriza por la presencia de nódulos de aspecto perlado nacarado de consistencia osteocartilaginosa en submucosa de tráquea y bronquios principales, respetando de manera característica la pared membranosa posterior [2].

La etiopatogenia permanece siendo una incógnita, sin embargo, las enfermedades respiratorias crónicas, traumatismos, amiloidosis, silicosis se han postulado como posibles agentes relacionados con su desarrollo [3]. La TOC es una entidad que se asocia con patologías como timoma, rinitis crónica atrófica, linfomas, quistes epidérmicos y miastenia gravis. Es imprescindible hacer un buen diagnóstico diferencial respecto a las lesiones de la TOC sobre todo con lesiones calcificadas secundarias a tuberculosis, carcinomas fibromas, con la policondritis o la Enfermedad de Wegener. Presentamos un caso de TOC diagnosticado en nuestro hospital a raíz de un proceso de rinitis crónica atrófica, realizamos una revisión sobre esta entidad, de cómo llegar a este diagnóstico y de las posibilidades terapéuticas.

\section{DESCRIPCIÓN}

Mujer de 67 años sin antecedentes medicoquirúrgicos relevantes. Consultó por halitosis secundaria a una rinitis crónica atrófica unilateral $y$, de forma ocasional, disestesias supraesternales. Se realizó una rinofibrolaringoscopia en la que se objetivaron lesiones nodulares de aspecto perlado nacarado en septum nasal y luz traqueal de aspecto irregular con lesiones de aspecto semejante a las visualizadas en mucosa nasal (Figura 1). Se solicitó TAC cervicotorácico en la que se describieron imágenes nodulares calcificadas que protruían desde la submucosa traqueal hacia el lumen sin comprometer de manera relevante la vía aérea y respetando la pared posterior traqueal (Figura 2). Ante las imágenes endoscópicas y las pruebas radiológicas la paciente fue diagnosticada de TOC concomitante con rinitis crónica atrófica (ocena). Actualmente se encuentra en seguimiento clínico y, tras la mejoría de su rinitis crónica atrófica, la halitosis, motivo de su consulta, ha mejorado.

\section{DISCUSIÓN}

La TOC fue descrita por primera vez en 1855 por Rokitansky [4]. Constituye una entidad benigna, poco diagnosticada, que afecta las vías respiratorias superiores. Su progresión es lenta, pero puede evolucionar desde un estado asintomático, hasta una enfermedad devastadora, generando insuficiencia respiratoria secundaria a obstrucción mecánica severa de la vía aérea [5]. Predomina entre la cuarta y sexta décadas de la vida sin establecerse una mayor incidencia según el género [6]. Su etiología y patogenia no son bien conocidas [7].

Se caracteriza clínicamente por la presencia de nódulos submucosos protruyendo hacia la luz traqueal y bronquios principales, afectando sobre todo la pared anterior y lateral traqueobronquial, en ocasiones se puede comprometer la laringe y los bronquios distales, aunque esto es todavía más infrecuente [5]. Así mismo se observa una indemnidad en la totalidad de los casos de la pared membranosa posterior de la tráquea. Las manifestaciones clínicas son muy variables. La mayoría de los pacientes son asintomáticos. Entre las manifestaciones clínicas más frecuentes se encuentran la dificultad respiratoria con los esfuerzos y la tos crónica. Otras manifestaciones clínicas pueden ser la hemoptisis, tos seca, infecciones recurrentes del tracto respiratorio inferior, atelectasias y dificultad para la intubación. El diagnóstico diferencial ha de hacerse especialmente con la amiloidosis traqueobronquial, entidad que genera, a diferencia de la TOC, un compromiso de la pared posterior de la tráquea. No obstante, existen casos descritos en la literatura en que ambas entidades coexisten. Otros diagnósticos diferenciales posibles son los granulomas tuberculosos calcificados, papilomatosis, sarcoidosis endobronquial, policondritis recidivante y enfermedad de Wegener, todas ellas afectan (al igual que en la amiloidosis) a la pared traqueal posterior [8]. Autores como Lazor y Cordier [9] sugieren que debe investigarse la existencia de TOC en todo paciente con rinitis atrófica (ocena) que presenta tos, disnea, hemoptisis, sensación de opresión torácica o infecciones traqueobronquiales recurrentes. De hecho, existen a día de hoy autores [10] que han relacionado TOC con ocena pero que desconocen el sustrato etiopatogénico de esta relación.

El diagnóstico clínico de TOC no es fácil. Es probable que la incidencia de TOC sea mucho 
mayor a la conocida y descrita en la bibliografía [11] ya que es una condición que se diagnostica de forma incidental.

Los síntomas (cuando se presentan) se superponen con los de otras patologías más frecuentes y la TOC no es tenida en cuenta, la mayor parte de las veces, como hipótesis diagnóstica. Para la confirmación del diagnóstico, autores como Prakash [5] sostienen que el diagnóstico de la TOC es endoscópico y que la biopsia no es necesaria. El diagnóstico definitivo se realiza por los hallazgos endoscópicos ya citados y aunque la biopsia no sea esencial para el diagnóstico, puede resultar muy útil para realizar un adecuado diagnóstico diferencial. Histopatológicamente se observa un acúmulo de fosfato cálcico en la submucosa de la vía aérea y proliferaciones benignas de hueso y cartílago produciendo las formaciones nodulares descritas. El tejido óseo puede estar calcificado o contener médula ósea hematopoyética. También es frecuente observar metaplasia escamosa de epitelio respiratorio [12]. Respecto a las pruebas de imagen, coincidimos con otros especialistas, tras la revisión bibliográfica realizada, que estas últimas tiene un papel importante principalmente de cara al diagnóstico diferencial. La TOC carece de tratamiento específico [13]. En la literatura se han discutido varios tipos de tratamientos, aunque no existe una evidencia demostrable. Entre las opciones se incluye la aplicación de Láser
YAG endobronquial, resección quirúrgica, colocación de stents y tratamiento sintomático tal como corticoides inhalados [14]. En los casos de importante compromiso de vía aérea, se podría valorar la necesidad de una traqueotomía de urgencia. Todos los tratamientos médicos se consideran paliativos, ya que no existe un tratamiento definitivo para erradicar la TOC. Los pacientes pueden necesitar periódicamente tratamiento con antibióticos y expectorantes debido las complicaciones secundarias que desarrollan, atelectasias o infecciones respiratorias recurrentes.

\section{CONCLUSIONES}

El diagnóstico de sospecha de TOC se estableció por el aspecto característico de las lesiones observadas mediante rinofibrolaringoscopia y fue corroborado con las pruebas de imagen practicadas. Consideramos de interés la descripción de este caso clínico ya que presenta la coexistencia de lesiones de TOC y rinitis crónica atrófica. Dado el escaso número de publicaciones respecto a esta asociación patológica, creemos interesante recordar al especialista en Otorrinolaringología las características clínicas de esta entidad, insistiendo en su posible asociación entre estas dos entidades infrecuentes: rinitis crónica atrófica u ocena y traqueobroncopatía osteocondrodisplásica.

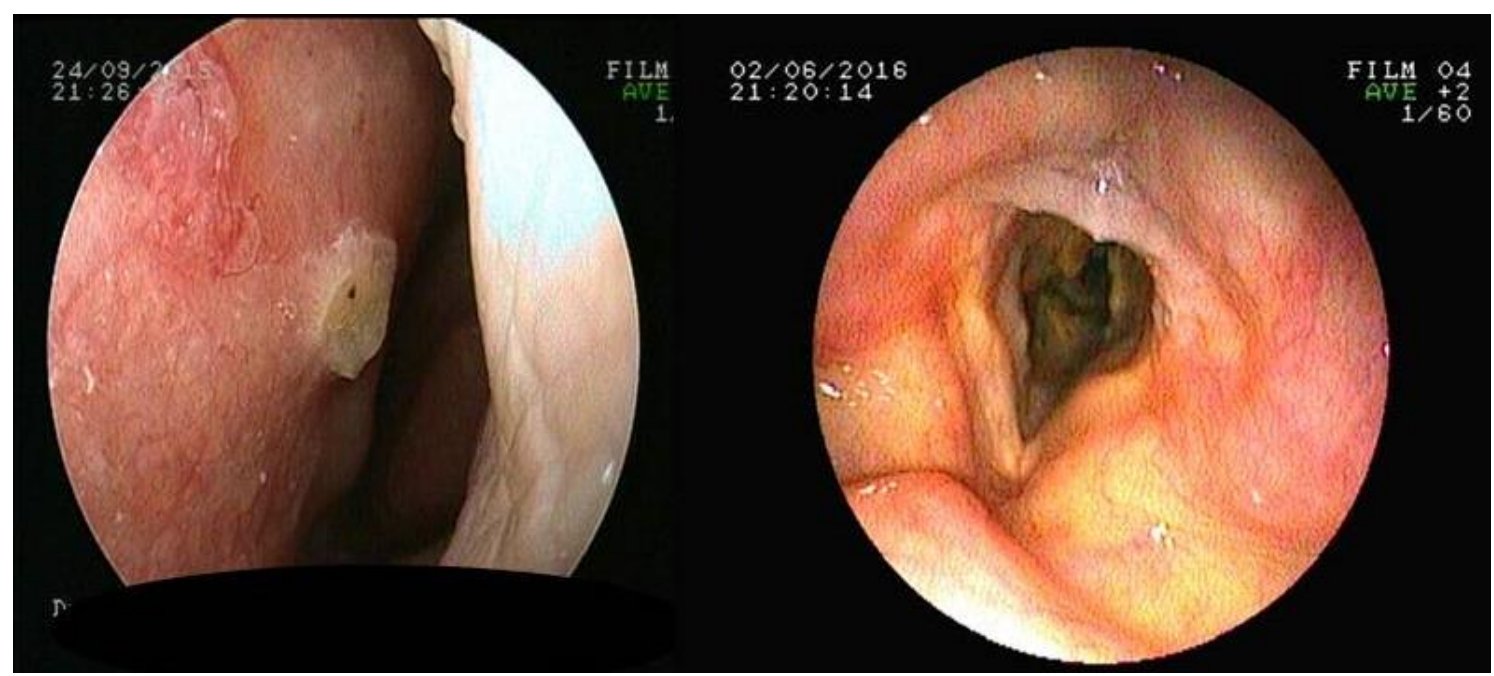

Figura 1. Traqueobroncopatía osteocondroplásica. Rinofibrolaringosocopia. Imagen nodular perlada en septum nasal sugestiva de calcificación submucosa (fosa nasal izquierda) e imágenes perladas de similar aspecto en mucosa traqueal. 


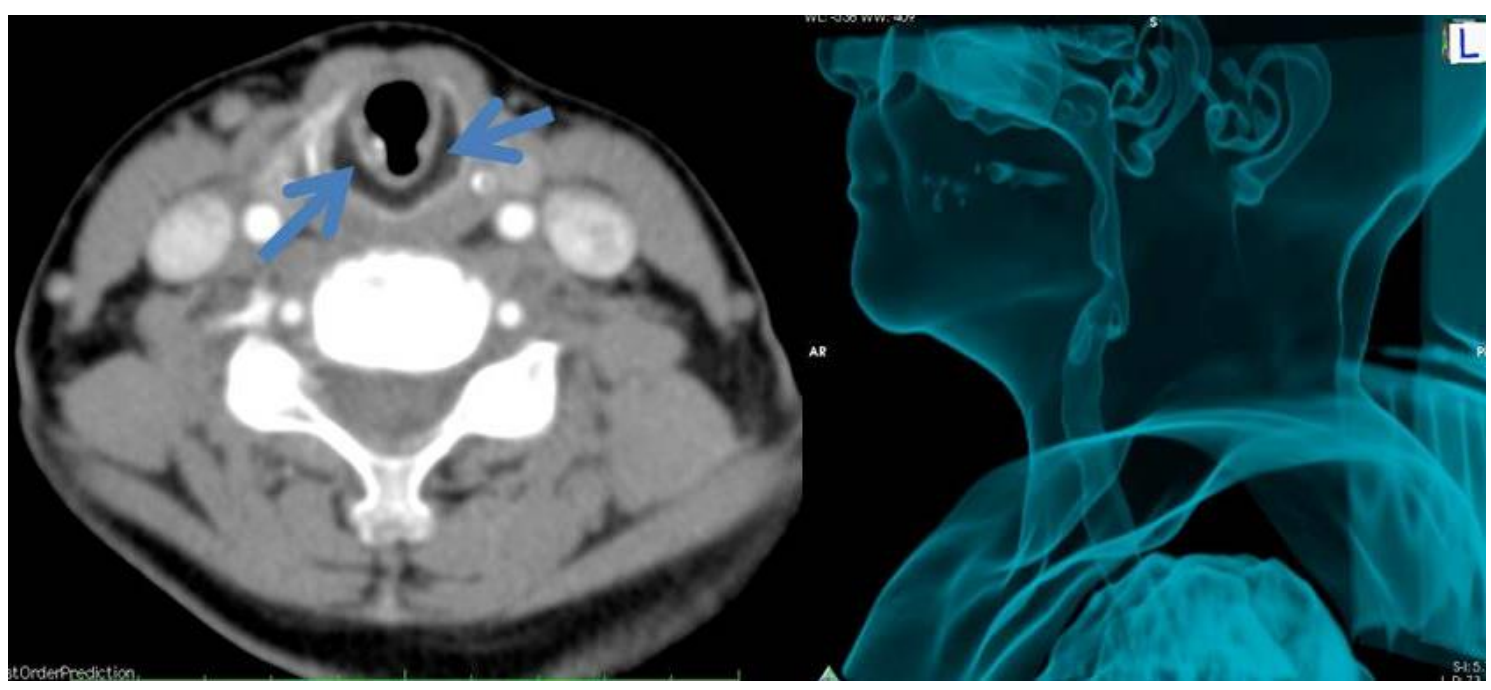

Figura 2. Traqueobroncopatía osteocondroplásica. Tomografía axial computarizada mostrando lesiones nodulares (flechas azules) compatibles con TOC. Reconstrucción 3D en que se objetiva irregularidad de luz traqueal.

\section{BIBLIOGRAFÍA}

1. Saint-Blancard $P$, Natali F, Vaylet F, Coutant G, L'Her P, Le Vagueresse R. [Osteochondroplastic tracheobronchopathy: 5 cases]. Rev Med Interne. 1997;18(11):8827.

2. Luo S, Wu L, Zhou J, Xu S, Yang Q, Li Y, et al. Tracheobronchopathia osteochondroplastica: two cases and a review of the literature. Int $\mathrm{J}$ Clin Exp Pathol. 2015;8(7):8585-90.

3. Thakur A, Yang T, Chen T, Rana N, Zhu B, Wei $X$, et al. Atypical presentation of tracheobronchopathia osteochondroplastica: Is chronic inflammation a perpetrator? Med Princ Pract. 2013;22:503-5.

4. Chroneou A, Zias N, Gonzalez AV, Beamis JF Jr. Tracheobronchopathia osteochondroplastica. An underrecognized entity? Monaldi Arch Chest Dis. 2008;69(2):65-9

5. .Prakash UB. Tracheobronchopathia osteochondroplastica. Semin Respir Crit Care Med. 2002;23(2):167-75.

6. Abu-Hijleh $M$, Lee D, Braman Ss. Tracheobronchopathia osteochondroplastica: a rare large airway disorder. Lung. 2008;186:353-9.
7. Shigematsu Y, Sugio K, Yasuda M, Sugaya $M$, Ono K, Takenoyama $M$, et al. Tracheobronchopathia osteochondroplastica occurring in a subsegmental bronchus and causing obstructiva pneumonia. Ann Thorac Surg, 2005;80(5):1936-8.

8. Jabbardarjani HR, Radpey B, Kharabian S, Masjedi MR. Tracheobronchopathia osteochondroplastica: presentation of ten cases and review of the literature. Lung. 2008;186(5):293-7.

9. Lazor R, Cordier JF. Tracheobronchopathia osteochondroplastica. Orphanet encyclopedia. June 2004. Disponible en: https://www.orpha.net/data/patho/GB/ukTO.pdf. [Citado el 20/02/2017].

10. Magro P, Garand G, Cattier B, Renjard L, Marquette $\mathrm{CH}$, Diot $\mathrm{P}$. Association of tracheo - bronchopathia osteochondroplastica and ozène. Rev Mal Respir. 2007;24:883.

11. White BD, Kong A, Southcott AM. Computed Tomography diagnosis of tracheobronchopathia osteochondroplastica. Australas Radiol. 2005; 49, 319-21.

12. Leske V, Lazor R, Coetmeur D, Crestani B, Chatté G, Cordier JF; Groupe d'Etudes et de Recherche sur les Maladies "Orphelines" Pulmonaires (GERM“O”P). Tracheobronchopathia osteochondroplastica: a study of 41 patients. Medicine. 2001,80.378-90. 
13. Celedon C, De Grazia J. 14. Simmons C, Vinh D, Donovan DT, Traqueobroncopatía osteocondroplástica: reporte de un caso y revisión de la literatura. Rev. Otorrinolaringol. Cir Cabeza Cuello 2010; 70: 147-52.

Ongkasuwan J. Tracheobronchopathia

Ostechondroplastica. Laryngoscope. 2016 Sep;126(9):2006-9. 